ББК 63.4

$$
\begin{gathered}
\text { Организация конференции и издание материалов проведены } \\
\text { при финансовой поддержке Российского фонда фундаментальных исследований, } \\
\text { проект № 19-09-20008 }
\end{gathered}
$$

Утверждено к печати Ученым советом ИИМК РАН

Редакционная коллегия тома II: А. В. Поляков, Е. С. Ткач (отв. редакторы), М. Т. Кашуба, Л. Б. Кирчо, Е. А. Черлёнок, В. Я. Стёганцева, А. И. Климушина

Рещензенты: д. и. н. Л. Б. Вишняцкий, д. и. н. А. А. Выборнов

Программный комитет конференции: академик РАН, д. и. н., проф. М. Б. Пиотровский (Государственный Эрмитаж, почетный председатель); д. и. н. В. А. Лапшин (ИИМК РАН, председатель); д. и. н. А. В. Головнёв (МАЭ РАН, сопредседатель); д. и. н. В. А. Дергачёв (Высшая антропологическая школа, Молдова, сопредседатель); д. и. н. И. Ф. Попова (ИВР РАН, сопредседатель); академик АН Республики Узбекистан, д. и. н., проф. Э. В. Ртвеладзе (сопредседатель); к. и. н. А. В. Поляков (ИИМК РАН, зам. председателя); к. и. н. В. А. Алёкшин (ИИМК РАН, зам. председателя); д. и. н. Ю. Е. Берёзкин (МАЭ РАН); Dr., Prof. Н. Бороффка

(Германский археологический институт, Германия); В. С. Бочкарёв (ИИМК РАН);

Dr. Э. Кайзер (Свободный университет Берлина, Германия); к. и. н. М. Т. Кашуба (ИИМК РАН); д. и. н. Л. Б. Кирчо (ИИМК РАН); к. и. н. А. В. Кияшко (Южный федеральный университет); к. и. н. П. Ф. Кузнецов (СГСПУ); к. и. н. Н. М. Малов (СНИГУ); к. и. н. В. П. Никоноров (ИИМК РАН); Ю. Ю. Пиотровский (Государственный Эрмитаж); д. и. н., проф. Д. Г. Савинов (Институт истории СПбГУ); к. и. н. В. Н. Седых (Институт истории СПбГУ); к. и. н. Н. Н. Скакун (ИИМК РАН); к. и. н. Н. Ф. Соловьёва (ИИМК РАН); к. и. н. А. И. Торгоев (Государственный Эрмитаж); к. и. н. Е. А. Черлёнок (Институт истории СПбГУ)

Организационный комитет конференции: к. и. н. А. В. Поляков (ИИМК РАН, председатель); к. и. н. В. А. Алёкшин (ИИМК РАН, зам. председателя); В. С. Бочкарёв (ИИМК РАН); к. и. н. М. Т. Кашуба (ИИМК РАН); д. и. н. Л. Б. Кирчо (ИИМК РАН);

А. И. Климушина (ИИМК РАН, отв. секретарь); к. и. н. В. П. Никоноров (ИИМК РАН); Ю. Ю. Пиотровский (Государственный Эрмитаж); В. Я. Стеганцева (ИИМК РАН); В. В. Терёхина (ИИМК РАН, МАЭ РАН, отв. секретарь); к. и. н. Е. С. Ткач (ИИМК РАН); И. Ж. Тутаева (Государственный Эрмитаж); к. и. н. Е. А. Черлёнок (Институт истории СПбГУ)

Древности Восточной Европы, Центральной Азии и Южной Сибири в контексте связей и взаимодействий в евразийском культурном пространстве (новые данные и концепции): Материалы Международной конференции, 18-22 ноября 2019 г., Санкт-Петербург. Т. ІІ. Связи, контакты и взаимодействия древних культур Северной Евразии и цивилизаций Востока в эпоху палеометалла (IV-I тыс. до н. э.). К 80-летию со дня рождения выдающегося археолога В. С. Бочкарёва. - СПб.: ИИМК РАН, Невская Типография, 2019. - 287 с.

ISBN 978-5-907053-35-9

DOI 10.31600/978-5-907053-35-9 
во всех областях распространения абашевской культуры, а на позднем этапе становятся, фактически, единственным вариантом. Абашевские топоры имели выраженную военнопрестижную функцию.

\section{Литература}

Бочкарёв В. С., Кузьмина О. В. 2015. О новом типе проушных топоров начальной поры эпохи поздней бронзы Доно-Волго-Уралья // Варёнов Д. В., Кочкина А. Ф., Сташенков Д. А (отв. ред.). Самарский край в истории России: Материалы межрегиональной науч. конф. Самара, 26-27 ноября 2014 г. Вып. 5. Самара. С. 107-114.

Бочкарёв В. С. 2017. Этапы развития металлопроизводства эпохи поздней бронзы на юге Восточной Европы // Stratum plus. № 2. С. 159-204.

Черных Е. Н. 1970. Древнейшая металлургия Урала и Поволжья. М.

\section{METAL AXES OF THE BRONZE AGE ABASHEVO CULTURE}

\section{Ol'ga V. Kuz'mina}

Samara Archaeological Society, Samara, Russia

Keywords: metal shafthole axes, Abashevo culture, type, variant.

This report is dedicated to analysis of metal axes of the Abashevo culture. Some single their examples (9 items) come from burials, settlements and hoards; other axes were accidental finds (68 items). There are two molds found at settlement-sites and one mold was retrieved from a burial. Abashevo axes are found throughout the main territory of the culture: the Middle Volga and South Urals (29 items); besides, they were encountered in transitional and adjacent areas, i. e. the Kama, Volga and Oka regions (49 items).

To the Abashevo type, axes with a short, hanging butt, strong bevel of the back above the sleeve, a long narrow wedge, a pointed abdomen and oval section of the sleeve are attributed. Abashevo axes are subdivided into variants according to blades and into groups according to proportions of the sleeve and its correlation with the blade. The variability of the axes reflects the history of the development and refining of the type. Axes had a battle function and were objects of high

\section{НОВЫЙ ПАМЯТНИК АБАШЕВСКОЙ КУЛЬТУРЫ ПРИУРАЛЬЯ}

П. Ф. Кузнецов ${ }^{\star}$, М. С. Чаплыгин ${ }^{* *}$

* Музей археологии Поволжвя Самарского государственного соииально-педагогического университета, Самара, Россия; ${ }^{* *}$ Стерлитамакский историко-краеведческий музей, Стерлитамак, Россия

DOI: 10.31600/978-5-907053-35-9-225-229

Ключевые слова: Приуралье, поздний бронзовый век, абашевская культура, блок «колесничих культур», хронология.

Курганный могильник Сарайсино-2, открытый М. С. Чаплыгиным, расположен в 250 м к ЮЮЗ от северо-западной окраины дер. Сарайсино (Стерлибашевский р-н Республики Башкортостан), на первой надпойменной террасе левого берега р. Кундряк (рис. 1, 1). В группе насчитывалось четыре кургана, три из которых (1, 2 и 3) вытянуты цепочкой по линии С-Ю, а четвертый расположен в нескольких десятках метрах западнее. Первоначальное количество насыпей могло быть больше, однако в результате эксплуатации

\footnotetext{
${ }^{1}$ Работа выполнена при финансовой поддержке РНФ, проект № 18-18-00137 «Контакты и взаимосвязи населения Урало-Поволжских и Казахстанских степей в период поздней бронзы и раннего железа».
} 
земельного участка часть их уничтожена. В 2009 г. отрядом Стерлитамакского историкокраеведческого музея проведены охранные раскопки кургана 1, западная пола которого оказалась подрезана в ходе эксплуатации карьера.

Под круглой земляной насыпью кургана 1 (диаметром 16 м и высотой 0,4 м) выявлено четыре погребения и жертвенный комплекс. Курган был возведен в эпоху бронзы над тремя захоронениями абашевской культуры. С абашевскими захоронениями связан и сооруженный на древнем горизонте жертвенный комплекс. Впоследствии в насыпь было впущено сарматское погребение (рис. 1, 2).

Абашевские погребения находились в центральной части подкурганной площадки. Они расположены в ряд по оси ЗСЗ-ВЮВ. Погребальные камеры подпрямоугольной формы размерами 2,60-2,88 × 1,38-1,86 м были незначительно заглублены в материк $(0,06-$ 0,22 м), длинными сторонами ориентированы по осям 3С3-ВЮВ и С3-ЮВ. Центральное погребение имело поперечное перекрытие из органики (жерди).

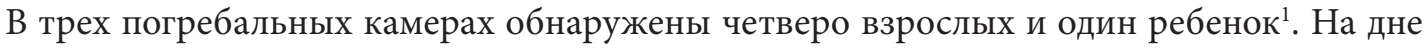
самой крупной могильной ямы (восточной в ряду захоронений) обнаружены скелет мужчины 18-20 л. и фрагменты скелета женщины 18-25 л., в засыпи погребальной камеры кости ребенка 10-14 л. В центральной яме были погребены двое взрослых, из которых удалось идентифицировать один скелет мужчины 18-20 л. В третьей (западной) камере обнаружен скелет мужчины 30-40 л.

В двух могилах погребенные были положены вытянуто на спине, головой на ВЮВ и ЮВ, в третьей - кости взрослого мужчины (30-40 лет) находились в разрозненном состоянии, возможно, вследствие вторичного захоронения останков.

В могильных ямах центрального и восточного захоронений погребальный инвентарь не обнаружен, но в 0,5 м от С 3 угла центральной камеры в слое погребенной почвы найден развал керамического светло-серого сосуда с примесью раковины в тесте (рис. 1,4$)$. Сосуд подколоколовидной формы с широким горлом (диаметром 18,7 см) и округлым туловом. Венчик отогнут, на внутренней стороне - ребро. В верхней трети тулова сосуд украшен каннелюрами и горизонтальным рядом перевернутых вершинами вниз заштрихованных треугольников. В могильной яме восточного захоронения сохранились отдельные элементы женского украшения: фрагмент нашивной бронзовой бляшки, пастовые бусины, бронзовые гладкие и рифленые пронизи (рис. 1,5$)$.

С абашевскими захоронениями связан жертвенный комплекс в северо-восточной части подкурганной площадки. Шесть крупных каменных плит размерами от 0,6 × 0,3 до 0,8 × 0,6 м находились на глубине 0,65-0,8 м от нулевой отметки в слое насыпи и на погребенной почве. Они располагались в горизонтальной плоскости на некотором расстоянии друг от друга. По длинной оси расстояние между крайними плитами не превышало 3 м. Каменные плиты были уложены над жертвенником из костей барана. Непосредственно под плитами были обнаружены три бараньи челюсти, лежащие на уровне погребенной почвы на расстоянии 0,7-0,8 м друг от друга. В 0,9 м к северу от крайней северо-западной плиты была найдена четвертая челюсть. Под плитами в слое погребенной почвы найдены фрагменты абашевского сосуда с примесью раковины в тесте (рис. 1, 3). Сосуд плавно профилированный, с широким горлом и округлым туловом. Под срезом венчика и по тулову сосуд украшен несколькими рядами горизонтальных каннелюр, разделенных горизонтальным рядом треугольников, направленных вершинами вверх и вниз. Ниже каннелюр нанесен горизонтальный ряд коротких наклонных линий, под ним - ряд вдавлений. Композицию завершает горизонтальный ряд заштрихованных ромбов. Орнамент нанесен мелкозубчатым штампом.

\footnotetext{
${ }^{1}$ Антропологические определения выполнены канд. биол. наук. В. В. Куфтериным (ИЭА РАН).
} 

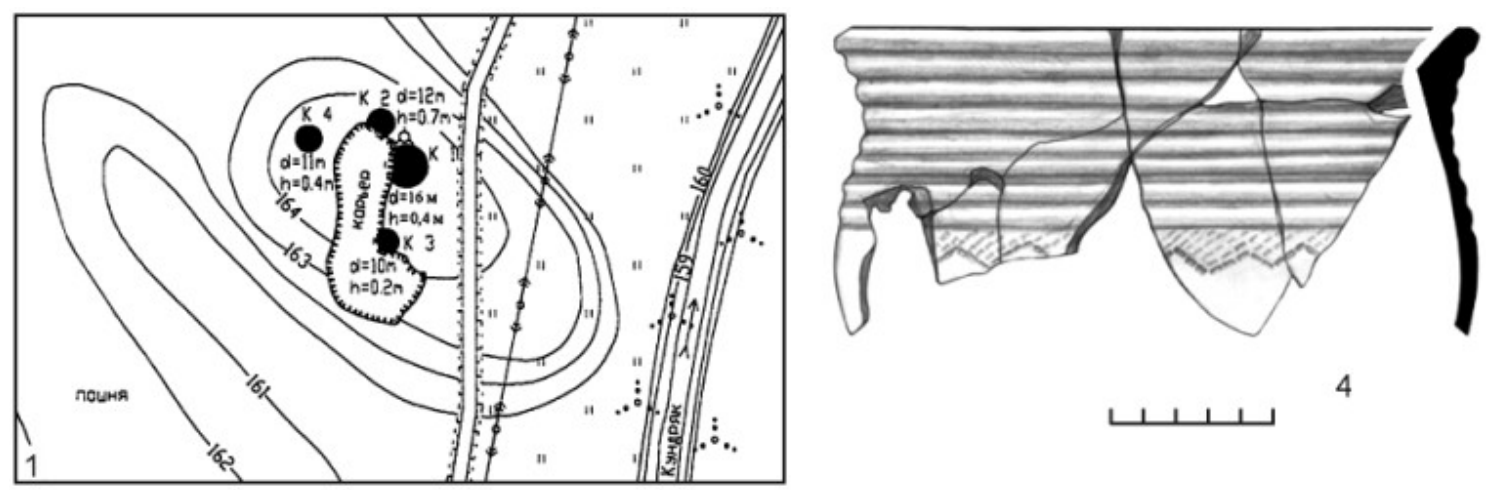

4

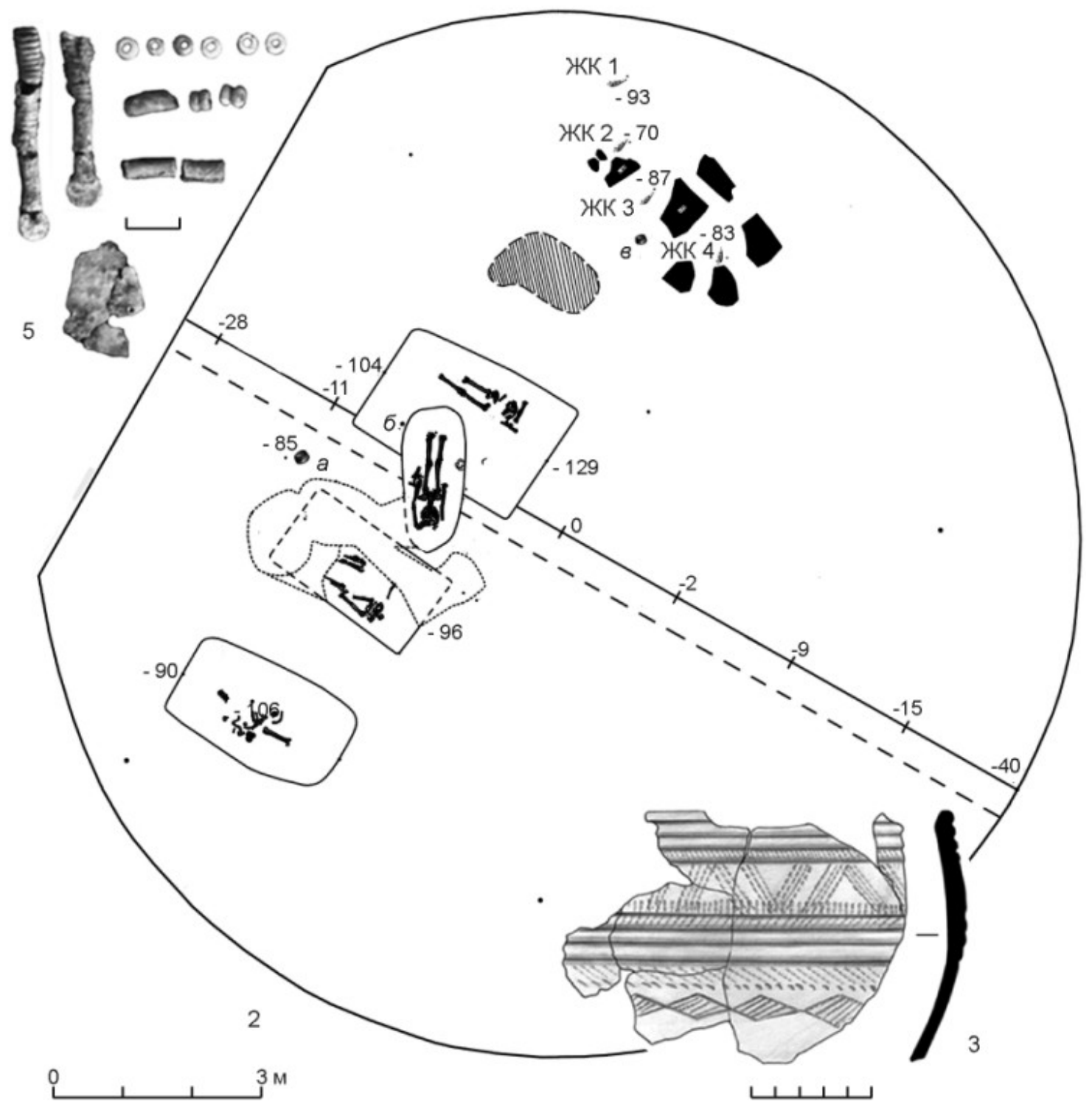

Рис. 1. Абашевские комплексы курганного могильника Сарайсино-2: 1 - план могильника; 2 - кург. 1, план; 3 - сосуд из жертвенного комплекса; 4 - сосуд, обнаруженный рядом с центральным погребением; 5 - украшения из восточного погребения 
По коллагену костей человека могильника Сарайсино-2 в Институте мониторинга климатических и экологических систем СО РАН были получены три радиоуглеродные даты. Это первые достоверные датировки абашевской культуры Приуралья (табл. 1).

Таблиц а 1

Результаты радиоуглеродного датирования абашевской культуры могильника Сарайсино-2

\begin{tabular}{|c|c|c|c|c|c|}
\hline \multirow{2}{*}{ № } & \multirow{2}{*}{$\begin{array}{c}\text { Шифр } \\
\text { лаборатории }\end{array}$} & Комплекс & \multirow{2}{*}{ Дата ВР } & \multicolumn{2}{|c|}{ Дата саl ВС } \\
\cline { 5 - 6 } & ИМКЭС-1017 & Сарайсино-2, кург. 1, погр. 6 & $3543 \pm 98$ & $2020-1740$ & $2200-1600$ \\
\hline 2 & ИМКЭС-1018 & Сарайсино-2, кург. 1, погр. 2 & $3632 \pm 80$ & $2140-1880$ & $2300-1700$ \\
\hline 3 & ИМКЭС-1021 & Сарайсино-2, кург. 1, погр. 7 & $3531 \pm 97$ & $2020-1730$ & $2150-1600$ \\
\hline
\end{tabular}

Калиброванные значения радиоуглеродного возраста находятся в интервале от конца III до первой трети II тыс. до н. э. В связи с тем, что все датированные погребения относятся к одной культуре и обнаружены под одной насыпью, мы посчитали возможным вычислить комбинированную радиоуглеродную дату для всех трех захоронений. В соответствии с программой OxCalv3.10 R_Combine Saraysino-2: 3578 \pm 52 ВР. Наиболее вероятный ее интервал - 2030-1870 cal BC (67,3 \%). Более широкий интервал показывает сумма вероятностей OxCalv310 значений всех радиоуглеродных датировок этого абашевского памятника: 2040-1760 cal BC (66,3 \%). Столь большой диапазон вероятностного положения датировок вызван тем обстоятельством, что все даты имеют весьма широкий доверительный интервал. При этом принципиально важно, что диапазон дат начинается, как минимум, в XXI в. до н. э., что подтверждает предположение о более ранней хронологической позиции абашевской культуры по отношению к синташтинской, покровской и потаповской культурам. Так, для абашевских памятников Среднего Поволжья хронологический интервал по радиоуглеродным датам определяется XXII-XIX вв. до н. э. (Кузнецов 2001: 179; Кузьминых, Мимоход 2016: 41). Вместе с тем, радиоуглеродная хронология не дает однозначного ответа о том, могут ли хотя бы частично быть синхронны абашевская культура и блок «колесничих культур».

В плане хронологического соотношения культур среднего и позднего бронзового веков представляется, что на современном этапе культурно-типологическая характеристика существенно уточняет данные радиоуглеродной хронологии. Принципиально важно, что при характеристике основных этапов металлопроизводства В. С. Бочкарёв выделил типы изделий, которые можно считать исключительно абашевскими: бляшки-розетки, «шитье», ребристые браслеты с плоским желобком, узковислообушные топоры, три типа кованых наконечников копий (Бочкарёв 2017: 169-170, табл. 1, ч. А). Он также выделил ряд других типов, которые перешли в последующее время - поздний бронзовый век. Для ранней группы позднего бронзового века им выделено 10 самостоятельных типов (Там же: 171), среди которых - эксклюзивные абашевские типы металлических изделий, но также имеются покровские, синташтинские и потаповские типы. Эти данные свидетельствуют, скорее, о хронологическом различии и преемственности рассматриваемых культур, чем об их частичном сосуществовании.

\section{Литература}

Бочкарёв В. С. 2017. Этапы развития металлопроизводства эпохи поздней бронзы на юге Восточной Европы // Stratum Plus. № 2. С. 159-204. 
Кузнецов П. Ф. 2001. Территориальные особенности и временные рамки переходного периода к эпохе поздней бронзы Восточной Европы // Кузнецов П. Ф. (ред.). К столетию периодизации В. А. Городцова бронзового века Восточной Европы. Самара. С. 178-182.

Кузьминых С. В., Мимоход Р. А. 2016. Радиоуглеродные даты Пепкинского кургана и некоторые вопросы хронологии средневолжской абашевской культуры// Алёкшин В. А. (ред.). Внешние и внутренние связи степных (скотоводческих) культур Восточной Европы в энеолите и бронзовом веке (V-II тыс. до н. э.): Материалы круглого стола, посвящ. 80-летию со дня рождения С. Н. Братченко (Санкт-Петербург, 14-15 ноября 2016 г.). СПб. С. 36-39.

\title{
NEW SITE OF THE ABASHEVO CULTURE IN THE URAL REGION
}

Pavel F. Kuznetsov ${ }^{\star}$, Mikhail S. Chaplygin ${ }^{\star *}$

${ }^{*}$ Museum of Archeology of the Volga Region, Samara State Socio-Pedagogical University, Samara, Russia; ${ }^{* *}$ Sterlitamak Museum of Local History, Sterlitamak, Russia

Keywords: Abashevo culture of the Middle Bronze Age, chariot cultures, Late Bronze Age, chronology.

This report presents materials from kurgan no. 1 at the cemetery of Saraysino-2 belonging to the Abashevo culture. Three of the burials have provided radiocarbon dates. Their joint consideration suggests that they are in the range of $21^{\text {st }}-19^{\text {th }}$ cent. BC.

\section{ЮНОШЕСКИЕ ПОГРЕБЕНИЯ С ОРУЖИЕМ И УКРАШЕНИЯМИ: ПРОБЛЕМА ИНТЕРПРЕТАЦИИ (ПО МАТЕРИАЛАМ ПАМЯТНИКОВ СИНТАШТИНСКОГО И ПЕТРОВСКОГО ТИПА)}

\author{
С. В. Сотникова \\ ООО «Центр археологических исследованииџ, Надым, Россия
}

DOI: 10.31600/978-5-907053-35-9-229-231

Ключевые слова: Южное Зауралье, Казахстан, эпоха поздней бронзы, памятники синташтинского типа, памятники петровского типа, юноческие социовозрастные объединения.

В синташтинских и петровских могильниках встречаются парные погребения подростков и детей старшего возраста лицом друг к другу. Для мужчин в парных захоронениях характерно положение на левом боку, а для женщин - на правом. Погребенных, как правило, сопровождает инвентарь в соответствии с их полом. Однако в подростковых и детских погребениях при каждом из скелетов может находиться как «мужской» (оружие), так и «женский» (украшения) инвентарь.

В могильнике Бестамак (Казахстан) погр. 5 содержалось парное захоронение. Погребенный, уложенный на левый бок, определен антропологом Л. Линдстромом как предположительно мужчина 18-22 л. Усопший, положенный на правый бок, определен им как предположительно подросток мужского пола 10-12 л. С обоими погребениями связан как «мужской» инвентарь, так и «женский» (Калиева, Логвин 2009: 49-50).

В могильнике Степное VII (Южное Зауралье) в погр. 19 покойники А и Б захоронены лицом друг к другу в «позе объятия». Погребенный А (8-9 л.) был уложен на правый бок и снабжен значительным количеством украшений, включая накосник, положение которого необычно. Накосник закрывает лицевую часть черепа, что, по мнению исследователей, было сделано намеренно. Погребенный Б (9 лет) был захоронен на левом боку, сопровождающий инвентарь при нем отсутствовал (Куприянова, Зданович 2015: 50-51).

В Синташтинском большом грунтовом могильнике (Южное Зауралье) в погр. 39 погребенные А и Б были захоронены скорченно, лицом друг к другу. С погребенным А, 